\title{
Multiple lymphomatous polyposis due to blastoid variant of mantle cell lymphoma diagnosed by com- puted tomography colonography and colonoscopy
}

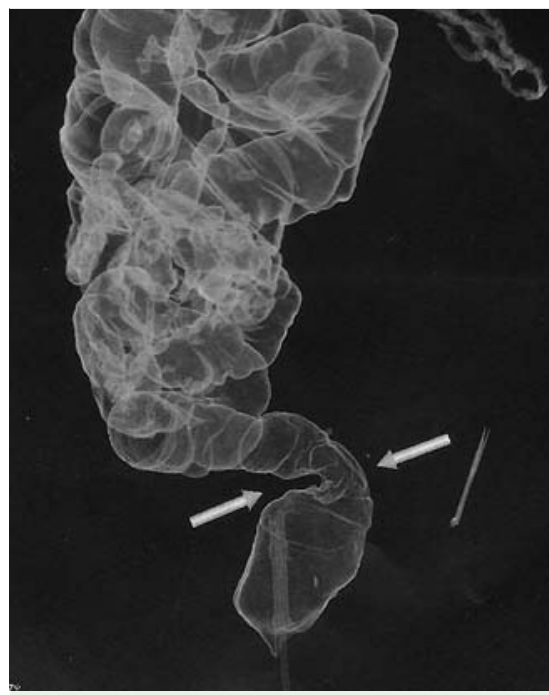

Fig. 1 Computed tomography colonography showing a lesion in the distal sigmoid colon that was suggestive of a colonic neoplasm.

An 88-year-old man with a past medical history of atrial flutter and congestive heart failure presented with rectal bleeding. Owing to his reluctance to undergo colonoscopy, he instead underwent computed tomography colonography, which showed one lesion in the splenic flexure and one lesion in the distal sigmoid colon, suggestive of colonic neoplasms ( $\bullet$ Fig. 1). The patient later did undergo a colonoscopy, which showed multiple yellowish, polypoid lesions dispersed throughout the colon ( Fig. $2 \mathrm{a}-\mathrm{c}$ ), some with erosions ( $\bullet$ Fig. 2d). Several biopsies were taken from different segments of the colon.

The biopsies all showed an extensive diffuse infiltration of the lamina propria by neoplastic lymphoid cells of intermediate/ large size, with irregular nuclei, fine chromatin, and scant cytoplasm ( Fig.3a). The mitotic index was moderate. Immunohistochemistry showed positivity for CD45, CD20, CD5, and cyclin D1, consistent with mantle cell lymphoma, blastoid variant $($ Fig.3b). A computed tomography scan showed multiple enlarged mesenteric lymph nodes and splenomegaly. As the patient did not have any obstructive symptoms, he was referred for treatment with chemotherapy.
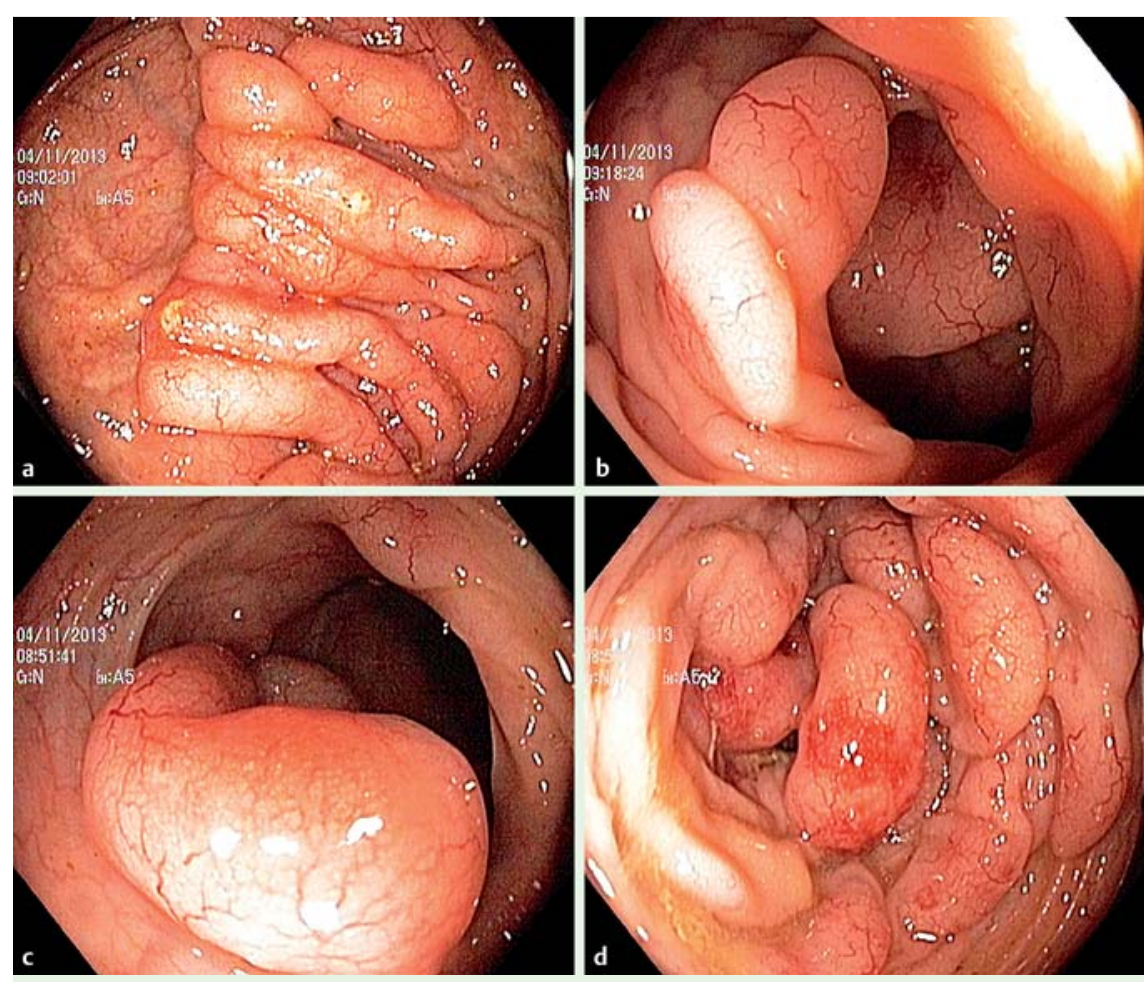

Fig. 2 Conventional colonoscopy images showing: a multiple yellowish, polypoid lesions dispersed throughout the colon; $\mathbf{b}$ the normal mucosa covering the polypoid lesions; $\mathbf{c}$ a central depression that is apparent in some of the polypoid lesions; $\mathbf{d}$ erosions that were present on some of the lesions in the distal colon.

Multiple lymphomatous polyposis (MLP) is an extremely rare form of primary gastrointestinal lymphoma that is characterized by multiple polyps formed by neoplastic lymphoid cells [1]. Most cases of MLP are found in mantle cell lymphoma. The blastoid variant of mantle cell lymphoma is so-called because of its blastoid cytology with large round-to-oval nuclei and prominent nucleoli, in contrast to the much more common classic variant of mantle cell lymphoma, which has nuclei of small-to-medium size with irregular contours [2,3]. Most of the cases of MLP previously reported in the literature have been in classic mantle cell lymphoma with typical cytology and low proliferation index.

\section{Endoscopy_UCTN_Code_CCL_1AD_2AC}

Eduardo Rodrigues-Pinto', Armando Ribeiro', Elsa Fonseca ${ }^{2}$, Guilherme Macedo ${ }^{1}$

${ }^{1}$ Gastroenterology Department, Centro Hospitalar São João, Porto, Portugal

2 Pathology Department, Centro Hospitalar São João, Porto, Portugal

\section{References}

1 Nguyen V, Nguyen B, Petris GD et al. Education and imaging. Gastrointestinal: gastrointestinal involvement of mantle cell lymphoma. J Gastroenterol Hepatol 2012; 27: 617

2 Saito T, Toyoda H, Yamaguchi $M$ et al. Ileocolonic lymphomas: a series of 16 cases. Endoscopy 2005; 37: 466-469

3 Morton JE, Leyland MJ, Vaughan Hudson G et al. Primary gastrointestinal non-Hodgkin's lymphoma: a review of 175 British National Lymphoma Investigation cases. Br J Cancer 1993; 67: 776-782

\section{Competing interests: None}




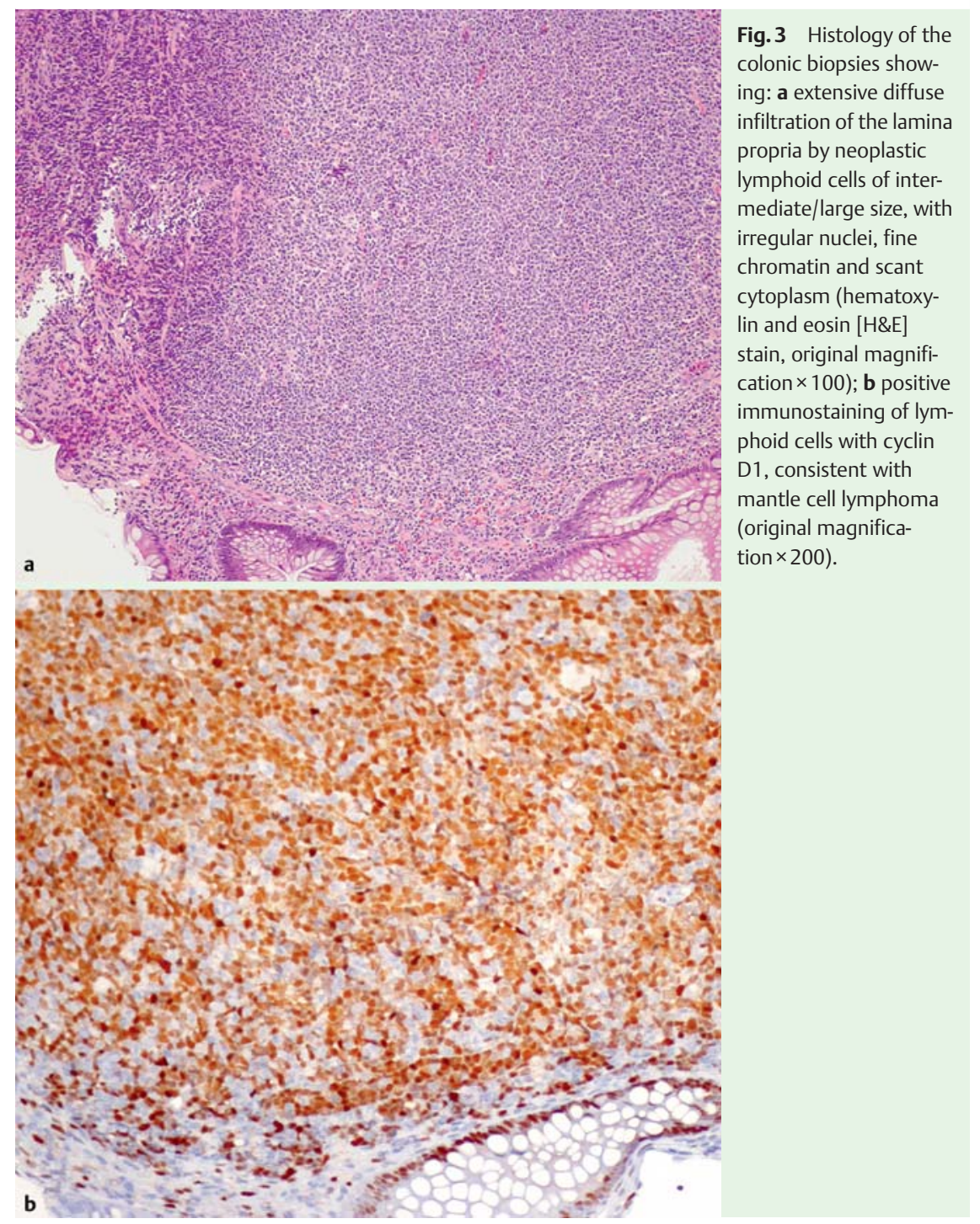

\section{Bibliography}

Dol http://dx.doi.org/

10.1055/s-0034-1365441

Endoscopy 2014; 46: E359-E360

(c) Georg Thieme Verlag KG

Stuttgart · New York

ISSN 0013-726X

\section{Corresponding author} Eduardo Rodrigues-Pinto, MD

Gastroenterology Department,

Centro Hospitalar São João

Al. Prof. Hernâni Monteiro 4200-319 Porto

Portugal

Fax: +351-22-5513601

edu.gil.pinto@gmail.com 